\title{
Representasi Kearifan Lokal Budaya Timur Tengah dalam Film “Aladdin (2019)" Produksi Walt Disney Pictures
}

\author{
Nada Salsabila, Diah Ayu Candraningrum \\ Salsabilanada30@gmail.com,diahc@fikom.untar.ac.id \\ Fakultas Ilmu Komunikasi Universitas Tarumanagara,
}

\begin{abstract}
This research examines the representation of Middle Eastern culture local wisdom contained in the film "Aladdin 2019" produced by Walt Disney Pictures. This study aims to examine the cultural symbols of the Middle East. The research method used in this study is a qualitative method with Charles Sanders Peirce's semiotic analysis which divides the sign into three elements namely sign, object and interpretant. Semiotics is the science that discusses or examines the meaning of a sign. The results showed that Middle Eastern cultural symbols in the film "Aladdin 2019" were displayed through 10 scenes selected in the film. Cultural symbols of the Middle East are shown through the habits of the people kissing the right and left cheeks every time they meet relatives, riding camels to travel, livelihoods of people who trade, princess clothes Jasmine and Sultan, building architecture made of bricks and domes as decoration and art that displays traditional Middle Eastern musical instrument namely Gambus. Some interesting facts in the film one of which is the making of the city "Agrabah" as a shooting setting which is a fictitious city in England and property made of authentic jewelry.
\end{abstract}

Keywords: culture, film, local wisdom, middle eastern, semiotic

\begin{abstract}
Abstrak
Penelitian ini mengkaji mengenai representasi kearifan lokal budaya Timur Tengah yang terdapat dalam Film "Aladdin 2019" Produksi Walt Disney Pictures. Penelitian ini bertujuan untuk mengkaji simbol-simbol budaya Timur Tengah. Metode penelitian yang digunakan dalam penelitian ini adalah metode kualitatif dengan analisis semiotika Charles Sanders Peirce yang membagi tanda menjadi tiga elemen yaitu tanda, objek dan interpretan. Semiotika adalah ilmu yang membahas atau mengkaji mengenai pemaknaan dari sebuah tanda. Hasil penelitian menunjukkan bahwa simbol-simbol budaya Timur Tengah dalam Film "Aladdin 2019" ditampilkan melalui 10 scene yang dipilih dalam film tersebut. Simbol-simbol Budaya Timur Tengah ditunjukkan melalui kebiasaan masyarakat cium pipi kanan dan kiri setiap bertemu kerabat, menunggangi unta untuk bepergian, mata pencaharian masyarakat yang berdagang, pakaian putri Jasmine dan Sultan, arsitektur bangunan berasal dari batu bata dan kubah sebagai hiasan serta kesenian yang menampilkan alat musik tradisional Timur Tengah yaitu Gambus. Beberapa fakta menarik dalam film tersebut salah satunya adalah pembuatan kota "Agrabah" sebagai latar syuting yang merupakan kota fiktif di Inggris dan properti yang terbuat dari perhiasan asli.
\end{abstract}

Kata Kunci: budaya, film, kearifan lokal, semiotika, timur tengah.

\section{Pendahuluan}

Film telah menjadi gambaran kehidupan suatu masyarakat, dimana seringkali menceritakan ulang kehidupan yang terjadi di masyarakat. Mulai dari bahasa, budaya, serta adat istiadat yang dimana film dianggap menjadi cerminan dalam masyarakat. 
Oleh karena itu, film dibuat sebaik mungkin sehingga dapat diterima dan menarik perhatian masyarakat (Danesi, 2010). Cerita yang ditayangkan dalam film dapat berupa cerita fiksi maupun non-fiksi. Film fiksi merupakan rangkaian film yang tercipta melalui imajinasi seseorang dan bukan terinspirasi dari kisah nyata. Sedangkan film non-fiksi merupakan rangkaian film yang diadaptasi dari kisah nyata yang semua unsur dalam cerita dibuat sesuai mungkin dengan realita.

Kearifan lokal merupakan adat dan kebiasan yang telah menjadi tradisi dilakukan oleh sekelompok masyarakat secara turun temurun yang hingga saat ini masih dipertahankan keberadaannya oleh masyarakat hukum adat tertentu di daerah tertentu (Alfian, 2013). Kearifan lokal merupakan identitas budaya masyarakat yang berupa nilai, norma, etika, kepercayaan, adat istiadat, dan aturan khusus yang diberlakukan oleh suatu kebudayaan masyarakat.

Dalam beberapa film juga terdapat unsur kearifan lokal, dengan menampilkan identitas budaya pada alur ceritanya. Salah satu film Hollywood yang mengandung kearifan lokal adalah "Aladdin". Film Aladdin mengambil tema kebudayaan Timur Tengah abad pertengahan dengan kondisi geografis yang berpasir, berdebu dan dikelilingi gurun serta bentuk arsitektur seperti rumah yang berbahan dari bata dan istana kerajaan yang berbentuk kubah, seperti merepresentasikan kehidupan di wilayah Timur Tengah (Ronaldy, 2015)

Timur Tengah merupakan kawasan yang secara budaya, politis dan geografis berada di wilayah Asia bagian barat dan sekitarnya. Negara ini memiliki curah hujan yang rendah dan beriklim panas dengan rata-rata suhu mencapai $49^{\circ} \mathrm{C}$ pada musim panas sehingga mengakibatkan sebagian wilayahnya adalah gurun pasir. Bahasa resmi masyarakat Timur Tengah ialah bahasa Arab. Kebudayaan Timur Tengah yang paling mencolok terlihat dari segi pakaian yang lebih tertutup dan tidak terbuka (Najib \& Tibek, 2014)

Film Aladdin ini menjadi salah satu film yang memiliki karakter yang kuat dan kental akan budaya terutama budaya Timur Tengah, karena menggambarkan kondisi budaya Timur Tengah pada abad pertengahan. Berdasarkan latar belakang di atas, rumusan masalah pada penelitian ini adalah "bagaimana representasi simbol-simbol kearifan lokal budaya Timur Tengah yang terdapat dalam Film Aladdin 2019 produksi Walt Disney Picture?" Tujuan dari penelitian ini adalah untuk mengetahui representasi simbol-simbol kearifan lokal budaya Timur Tengah dalam Film Aladdin 2019.

\section{Film Sebagai Komunikasi Massa}

Komunikasi massa adalah proses komunikasi yang berlangsung dimana pesannya disampaikan dari seseorang atau suatu organisasi melalui perantara media massa yang ditujukan kepada masyarakat luas (Fiske, 2012).

Media cetak adalah salah satu media yang berbentuk tulisan, sedangkan media elektronik adalah media yang menggunakan perantara alat elektronik seperti televisi, radio, film dalam menyampaikan pesan kepada masyarakat. Sedangkan, film adalah salah satu komunikasi massa yang berbentuk audio visual untuk menyampaikan suatu pesan kepada khalayak luas.

\section{Representasi}

Menurut Stuart Hall (dalam Wibowo, 2013), representasi adalah salah satu praktek dari sebuah kebudayaan. Seseorang dikatakan berasal dari kebudayaan yang sama, jika hidup di tempat yang sama dan memiliki bahasa yang sama. Dapat pula diartikan representasi sebagai pemaknaan kembali oleh pemikiran manusia yang 
disampaikan menggunakan bahasa sendiri. Sedangkan menurut Fiske, representasi merupakan suatu proses adanya realitas yang disampaikan dalam komunikasi, katakata, bunyi, citra, atau kombinasinya. Representasi memiliki konsep yang dapat berubah-ubah, representasi pada dasarnya bekerja melalui hubungan tanda dan makna. Representasi akan berubah mengikuti perkembangan kebutuhan yang diperlukan oleh manusia sendiri; manusia sendiri selalu berubah dan bergerak maju ke depan. Karena pola pikir dan cara pandang yang dimiliki oleh setiap manusia berbeda, maka akan mengakibatkan hasil pemaknaan yang berbeda. Hasil representasi ini kemudian akan dikonstruksi dan dibangun sehingga menjadi proses penandaan, praktik yang membuat suatu hal menjadi memiliki makna (Junaidi \& Yustiana, 2019).

\section{Kearifan Lokal}

Kearifan lokal adalah pandangan hidup dan pengetahuan serta berbagai strategi kehidupan yang berwujud aktivitas yang dilakukan oleh masyarakat lokal dalam menjalankan kehidupan (Permana, 2010).

Kearifan pada umumnya telah dimiliki dan menjadi tradisi masyarakat lokal. Kearifan-kearifan tersebut terbentuk dalam perilaku masyarakat lokal ketika berinteraksi dengan lingkungan hidupnya yang diwariskan oleh para leluhur.

Dapat disimpulkan kearifan lokal merupakan gagasan setempat yang tertanam dan diikuti oleh anggota masyarakatnya juga berbagai pola tindakan dan hasil budaya. Dengan kata lain, semua bentuk adat kebiasaan atau etika yang menuntun seluruh perilaku manusia dalam menjalani suatu kehidupan.

\section{Semiotika Charles Sanders Peirce}

Menurut Morissan (2013), semiotika merupakan studi mengenai tanda (sign) dan simbol yang merupakan suatu hal penting dalam komunikasi. Semiotika mencakup teori utama yang mengenai tanda mewakili objek, ide, situasi, keadaan, perasaan yang berada di luar diri. Tanda tidak hanya memberikan cara dalam mempelajari komunikasi, tetapi juga memiliki efek yang besar untuk setiap aspek yang digunakan dalam teori komunikasi.

Ahli filsafat yang menjelaskan pertama kali memunculkan ilmu tanda pada abad ke-19 adalah Charles Sanders Peirce. Peirce menjelaskan mengenai ilmu tanda ini merujuk pada penggunaan tanda pada bahasa. Peirce menjelaskan mengenai makna yang terkandung dalam bahasa. Peirce menyebut teorinya sebagai "grand theory" dalam semiotika karena Peirce bersifat menyeluruh, penjelasannya terstruktur dari semua penandaan. Peirce ingin mengidentifikasi dasar-dasar dari sebuah tanda dan menggabungkan kembali semua komponen yang ada (Wibowo, 2013).

Teori Segitiga Tanda yang dikenalkan oleh Charles Sanders Peirce meliputi :

a. Tanda (sign): bentuk fisik yang diserap oleh pancaindera dan mengacu pada sesuatu yang berfungsi sebagai tanda. Sign meliputi Qualisign (tanda berdasarkan sifatnya), Singsign (tanda yang sesuai bentuk kenyataan), Legisign (tanda sebagai peraturan yang berlaku).

b. Objek: merujuk pada tanda. Objek meliputi Icon (tanda memiliki kesamaan dengan objek yang dimaksud), Index (tanda yang memiliki hubungan sebab akibat), Symbol (tanda berdasarkan kesepakatan bersama),

c. Interpretan: merujuk pada makna dari tanda. Interpretan meliputi Rhema (lambang dan makna tanda dapat dikembangkan), Decisign (lambang dan interpretan terdapat hubungan yang benar), Argument (lambang dan tanda memiliki sifat umum). 


\section{Metode Penelitian}

Penelitian ini menggunakan pendekatan kualitatif. Denzin dan Lincoln (dalam Moleong, 2017) menyatakan bahwa yang dimaksud dengan pendekatan kualitatif adalah penelitian yang tidak didasarkan pada hitung-hitungan. Pendekatan ini dengan maksud menafsirkan fenomena yang terjadi dan dilakukan dengan jalan melibatkan berbagai metode yang ada. Pada penelitian kualitatif, metode yang biasanya dimanfaatkan adalah wawancara, penggunaan dokumen yang relevan. Penelitian ini bersifat deskriptif dimana tujuan penelitian ini untuk menggambarkan sesuatu, seperti kondisi maupun sebuah peristiwa (Arikunto, 2010). Penelitian ini menggunakan metode semiotika model Peirce. Analisis tersebut untuk meneliti film "Aladdin 2019" produksi Disney berdurasi 128 menit yang mengandung kearifan lokal Timur Tengah. Model Semiotika Peirce terkenal dengan segitiga makna yang terdiri dari tanda (sign), objek, dan interpretan. Data-data tersebut kemudian ditafsirkan dengan referensireferensi yang terkait dengan penelitian.

Metode yang digunakan untuk mengumpulkan data adalah scene film "Aladdin 2019", wawancara, studi kepustakaan. Narasumber yang akan menjadi subyek penelitian ini adalah pengamat budaya yang paham terkait budaya Timur Tengah. Subjek penelitian ini adalah Ade Solihat, S.S., M.A selaku Dosen Prodi Sastra Arab UI. Dalam penelitian ini peneliti menggunakan analisis triangulasi data dengan sumber dan metode untuk menguji keabsahan data. Menurut Patton (dalam Pujileksono, 2015) dengan menggunakan teknik triangulasi sumber, peneliti membandingkan hasil wawancara yang diperoleh dari sumber informan ahli sebagai pembanding untuk mengecek keabsahannya. Selain itu, peneliti juga menggunakan teknik triangulasi metode, dengan melakukan pengecekan hasil penelitian yang telah didapat dengan teknik pengumpulan data diantaranya wawancara dengan informan ahli, observasi, studi pustaka serta dokumentasi, sehingga derajat kepercayaan data dapat terverifikasi dengan baik.

\section{Hasil Temuan dan Diskusi}

Aladdin 2019 merupakan sebuah film fiksi musikal yang diproduksi oleh Disney dan disutradarai oleh Guy Ritchie, dan skenario ditulis oleh Ohn August. Film ini adalah remake dari film animasi Disney tahun 1992 dengan judul yang sama. Ceritanya diambil dari kumpulan cerita rakyat Timur Tengah yaitu legenda 1001 malam. Disney membangun kota fiktif yaitu "Agrabah" yang menjadi latar tempat dalam film Aladdin (2019) yang terinspirasi dari negara-negara Timur Tengah seperti Maroko, Persia dan Turki (Nikki, 2019).

Aladdin menceritakan tentang seorang anak jalanan yang jatuh cinta dengan seorang putri kerajaan bernama Jasmine, kemudian ia menemukan lampu ajaib berisi jin yang bisa mewujudkan semua keinginannya secara instan untuk menikahi putri sultan. Tetapi pada akhirnya, ia menyadari perbuatannya merupakan tindakan yang salah karena ia harus membohongi semua orang dengan mengaku sebagai pangeran kerajaan dari kota lain dan menutupi identitas aslinya sebagai anak jalanan di kota tersebut.

Film Aladdin 2019 dibuat dengan tampilan live action yang berbeda dengan film animasi terdahulu, sehingga penonton dapat merasakan atmosfer baru dan tetap memiliki pesan-pesan yang tersembunyi atau tersirat mengenai representasi kearifan lokal dalam film ini. Peneliti mengambil 10 scene yang dianggap kuat 
merepresentasikan kearifan lokal dalam Film Aladdin 2019. Temuan yang didapatkan berdasarkan dari hasil wawancara dengan narasumber ahli budaya. Peneliti menemukan fakta baru, film ini tidak hanya menggambarkan budaya Timur Tengah, melainkan budaya lain salah satunya India, terlihat dari corak dan warna pakaian yang mencolok (Widiana, 2017).

Menurut Ade, Film Aladdin 2019 ini merupakan reproduksi budaya barat dalam membangun representasi budaya Timur Tengah. Banyak hal yang direkayasa oleh pembuat film tersebut seolah-olah memang benar-benar menggambarkan kebudayaan Timur Tengah. Jika dilihat dari setting, unsur Timur Tengah terasa. Namun untuk penggambaran tokoh utama dan beberapa ikon dalam film tersebut lebih menggambarkan budaya India dan juga budaya barat. Namun, karena film ini imajinasi sutradara dan produser sehingga dianggap sah untuk dibuat semenarik mungkin walaupun tidak benar-benar menggambarkan budaya Timur Tengah.

Mayoritas masyarakat Indonesia menganggap bahwa film ini mengandung unsur budaya Timur Tengah, dengan melihat dari penggambaran setting. Jika dikaji lebih dalam, film ini lebih menggambarkan reproduksi budaya barat dalam menampilkan dan merepresentasikan film yang mengandung kebudayaan Timur Tengah.

Jika Film Aladdin 2019 ingin menggambarkan budaya Timur Tengah, seharusnya benar-benar menampilkan unsur budaya yang kental. Adat istiadat masyarakat Timur Tengah dalam menjalani kehidupan harus benar-benar ditunjukkan. Akan tetapi, film ini hanya memberikan setting wilayah Timur Tengah, namun unsur budaya Timur Tengah tidak banyak ditunjukkan. Bahkan, budaya barat lebih mendominasi di film ini. Hal ini membuktikan kalau anggapan kebanyakan masyarakat yang menganggap bahwa Film Aladdin 2019 merupakan film yang kental dengan budaya Timur Tengah tidak sepenuhnya benar.

Budaya merupakan suatu hal yang tidak pernah lepas dari kehidupan manusia di berbagai negara. Setiap negara pasti memiliki budaya yang menjadi ciri khas negara tersebut, karena budaya merupakan identitas dan kekayaan dari suatu negara. Budaya bisa berasal dari negara itu sendiri atau dari negara lain yang telah terkulturasikan menjadi budaya setempat. Seperti halnya beberapa budaya di Indonesia yang ternyata berasal dari negara Timur Tengah dan telah terakulturasi menjadi budaya setempat.

Akulturasi budaya membuat budaya itu sendiri dikenal luas dan diterima baik oleh banyak orang. Industri perfilman sudah banyak memproduksi film yang mengangkat tema kebudayaan. Film Aladdin terlihat mengandung budaya lokal Timur Tengah, namun ternyata film tersebut mengandung beberapa kebudayaan tidak hanya budaya Timur Tengah, melainkan percampuran budaya barat dan India yang membuat hal tersebut menjadi menarik, memperlihatkan ciri khas budaya dari beberapa negara tetapi dikemas dalam satu cerita.

\section{Simpulan}

Melalui film “Aladdin 2019" masyarakat dapat mengetahui budaya Timur Tengah apa saja yang ditampilkan dalam film tersebut dari segi arsitektur bangunan, pakaian, kesenian dan kebiasaan masyarakatnya. Film Aladdin 2019 tidak hanya menggambarkan kebudayaan Timur Tengah namun terdapat budaya lain seperti India. Hal ini terlihat dari corak dan pemilihan warna yang mencolok yang merupakan ciri khas dari pakaian India. Peneliti menemukan fakta bahwa anggapan masyarakat yang menyatakan Film Aladdin berasal dari Timur Tengah dan banyak mengandung 
kebudayaan Timur Tengah adalah tidak sepenuhnya benar. Pada kenyataannya, Film Aladdin 2019 merupakan reproduksi budaya Barat dalam merepresentasikan kebudayaan Timur Tengah, sehingga terlihat seperti film yang berasal dari Timur Tengah.

\section{Ucapan Terima Kasih}

Peneliti mengucapkan terimakasih kepada Ade Solihat, S.S., M.A. selaku Dosen Sastra Arab Universitas Indonesia yang telah memberikan kesediaan menjadi narasumber untuk bekerjasama selama proses penelitian ini serta kedua orangtua dan kakak-kakak juga rekan-rekan peneliti yang mendukung dan membantu dalam penelitian ini.

\section{Daftar Pustaka}

Alfian, Magdalia. (2013). Potensi Kearifan Lokal Dalam Pembentukan Jati Diri dan Karakter Bangsa, Prociding The $5^{\text {th }}$ International Conference on Indonesia Studies: Ethnicity and Globalization, Jakarta.

Arikunto. (2010). Prosedur Penelitian: Suatu Pendekatan Praktek. Jakarta: Rineka Cipta.

Danesi, Marcel. (2010). Pengantar Memahami Semiotika Media. Yogyakarta: Jalasutra

Fiske, John. (2012). Pengantar Ilmu Komunikasi. Jakarta: PT. Raja Grafindo Persada Junaidi, Alex., \& Yustiana, Melia. (2019). Representasi Feminisme dalam Film Marlina si Pembunuh dalam Empat Babak (Analisis Semiotika Roland Barthes). Jurnal Koneksi. 3 (1). Diakses pada 15 Januari 2020 Pukul 19:27 WIB. Terarsip https://journal.untar.ac.id/index.php/koneksi/article/view/6154/4214

Morissan. (2013). Teori Komunikasi: Individu Hingga Massa. Jakarta: Kencana Prenada Media Group

Najib, Nur., \& Tibek, Siti. (2014). Value and Culture in Aladdin Animated Film. International Journal of West Asian Studies, 6 (1), 63-76. Diakses pada 13 September 2019. Terarsip di: http://ejournal.ukm.my/ijwas/article/view/8723

Nikki, Anasthasia (2019, Mei 21). Fakta Menarik di Balik Live Action Film Aladdin Buatan Disney. Tenang, Ini Bukan Spoiler https://www.hipwee.com/list/beberapa-fakta-menarik-dari-aladdin-yangditunggu-sejak-27-tahun-perilisan-film-live-actionnya/ diakses pada 15 Januari 2020 pukul 08:48 WIB

Permana, C. K. (2010). Kearifan Lokal Masyarakat Baduy dalam Mengatasi Bencana. Jakarta: Wedatama Widia Sastra.

Pujileksono, Sugeng (2015) Metode Penelitian Komunikasi Kualitatif. Malang : Intrans Publishing.

Ronaldy, Taufik. (2015). Representasi Umat Islam Dalam Film Barat. Skripsi. Diakses pada 13 September 2019 Pukul 01:10 WIB. Terarsip di: http://eprints.umm.ac.id/45656/

Solihat, Ade (2019, November 08) Wawancara Pribadi

Vera, Nawiroh. (2014) Semiotika Dalam Riset Komunikasi. Bogor: Ghalia Indonesia

Wibowo, Indiawan Seto. (2013). Semiotika Komunikasi Aplikasi Bagi Penelitian dan Skripsi Komunikasi. Jakarta: Mitra Wacana Media 
Nada Salsabila, Diah Ayu Candraningrum: Representasi Kearifan Lokal Budaya Timur Tengah dalam Film “Aladdin (2019)” Produksi Walt Disney Pictures

Widiana, Wila (2017, Oktober 23). Saree, Kain Warna-warni dari India https://bobo.grid.id/read/08678390/saree-kain-warna-warni-dari-india diakses pada 11 Januari 2020 pukul 15:40 WIB 